\title{
EFFICIENT THREE-DIMENSIONAL MODELLING OF HIGH-RISE BUILDING STRUCTURES
}

\author{
Mohammed JAMEEL ${ }^{\mathrm{a}}$, A. B. M. Saiful ISLAM ${ }^{\mathrm{a}}$, Mohammed KHALEEL ${ }^{\mathrm{a}}$, Aslam AMIRAHMAD ${ }^{\mathrm{b}}$ \\ ${ }^{a}$ Department of Civil Engineering, University of Malaya, Kuala Lumpur, Malaysia \\ ${ }^{b}$ Department of Civil Engineering, Salman Bin Abdulaziz University, Al-Kharj, Saudi Arabia
}

Received 5 Jan 2012; accepted 16 Jan 2012

\begin{abstract}
A multi-storey building is habitually modelled as a frame structure which neglects the shear wall/slab openings along with the inclusion of staircases. Furthermore, the structural strength provided by shear walls and slabs is not precisely incorporated. With increasing building height, the effect of lateral loads on a high-rise structure increases substantially. Inclusion of shear walls and slabs with the frame leads to improved lateral stiffness. Besides, their openings may play imperative role in the structural behaviour of such buildings. In this study, 61 multi-storey building configurations have been modelled. Corresponding analyses are performed to cope with the influence of shear walls, slabs, wall openings, masonry walls and staircases in addition to frame modelling. The finite element approach is used in modelling and analysis. Structural responses in each elemental combination are evaluated through equivalent static and free vibration analyses. The assessment reveals that inclusion of only slab components with frame modelling contributes trivial improvement on structural performance. Conversely, the presence of shear wall slabs with frame improves the performance noticeably. Increasing wall openings decreases the structural responses. Furthermore, it is not recommended to model staircases in addition to frame-slab-shear wall modelling, unless the effect of wall openings and slab openings is adequately considered.
\end{abstract}

Keywords: efficient modelling; high-rise buildings; wall opening; staircase; frame-slab-shear wall model; masonry wall.

Reference to this paper should be made as follows: Jameel, M.; Islam, A. B. M. Saiful; Khaleel, M.; Amirahmad, A. 2013. Efficient three-dimensional modelling of high-rise building structures, Journal of Civil Engineering and Management 19(6): 811-822. http://dx.doi.org/10.3846/13923730.2013.799096

\section{Introduction}

Incorporation of wall openings and staircase providing slab openings are essential in building structures, which should be precisely investigated. Furthermore, the inclusion of shear walls and slabs improves the lateral stiffness, and thus the structural performance of a building. Shariq et al. (2008) mentioned that the adequate lateral stiffness in buildings may be achieved by providing shear walls, which resist the lateral forces primarily due to their high in-plane stiffness. In multi-storey buildings, shear walls placed in the form of elevator cores, enclosed stairways, shear boxes or facade shear walls are capable of providing considerable lateral stiffness to the structure to enable it to resist horizontal loadings such as earthquakes and wind (Madsen et al. 2003). These components of structures bear wall/slab opening and staircases are additionally added. These corresponding studies have been carried out by several researchers such as Kim and Lee (2003, 2005), Kim et al. (2005), Kim and Foutch (2007) and Lin et al. (2011). Combining a frame system and a shear wall system is appropriate for a multi-storey building with shear walls arranged around the lift shafts and stair wells. Both shear walls and frames participate in resisting the lateral loads resulting from earthquakes or wind or storms, and the portion of the forces resisted by each one depends on its rigidity, modulus of elasticity and its ductility, and the possibility to develop plastic hinges in its parts (Wang et al. 2001; Islam et al. 2012a, b; Balkaya, Kalkan 2003, 2004). Simulation-based assessment and multiple criteria assessment works on multi-storey buildings have been carried out by Jameel et al. (2011)

In structural modelling, it is required to consider the wall openings and slab opening since openings commonly exist in multi-storey buildings, for functional reasons (such as doors, windows, air ducts, etc.) as well as to accommodate staircases and lift shaft. These wall openings may reduce the lateral stiffness of a building structure. Experimental tests indicated that slender shear walls containing openings are susceptible to unpredictable failure characteristics due to buckling and excessive cracking around the openings (Guan et al. 2010). Realising the importance of considering wall openings in structural design and analysis, more researchers have incorporated wall openings into their research studies (Shariq et al. 2008; Dolšek, Fajfar 2008a).

Moreover, RC frame with masonry infill is a popular structural system in many parts of the world. Infill panels 
can change the overall resistance and stiffness of buildings (Borzi et al. 2008). According to findings of Kose (2009), $\mathrm{RC}$ frames with infill shear walls had a shorter period of approximately $5-10 \%$, compared with RC frames without infill shear walls regardless of whether they had shear walls or not. Dolšek and Fajfar (2008a, b) have shown that 'masonry infill highly increases the stiffness and strength of a structure as long as the seismic demand does not exceed the deformation capacity of the infills; after that, both the global stiffness and the global strength strongly deteriorate' and 'the infills can completely change the distribution of damage throughout the structure'.

Along with the shear walls and slabs of a multistorey building, staircases can also significantly increase the building resistance (Borzi et al. 2008). However, very limited studies have been done on the effect/role of staircase on the lateral stiffness or structural response of multi-storey buildings. Experimental assessment of vibration serviceability of stair systems has been performed by Kim et al. (2008), involving steel stair system and RC stair system. Theoretically, staircase, which is similar to an inclined slab that is connecting slabs of adjacent storeys, may acts as a diagonal brace between floors, thus contributing to both vertical and horizontal stiffness of the structure. This may help to limit the lateral deflection of the building subjected to wind load and/ or seismic force.

Although numerous studies have been performed on multi-storey high-rise buildings, proper research on efficient design which includes accurate effect of wall/slab openings and staircases is still lacking. It is detected that shear walls (both RC shear wall and masonry wall) and slabs offer some structural strength, thus contributing to the lateral stiffness of the structure, which might lead to economical design and material savings. Simultaneously, wall openings needs to be taken into consideration in structural analysis to avoid overestimating the structural stiffness of a designed building. Studies can be done to investigate the effect of considering shear walls, slabs and wall openings in modelling and analysis, as compared to the conventional frame structure concept. Furthermore, it is still unknown to what extent the staircase contributes to the lateral stiffness of the structure.

So the objectives of the study are:

- To carry out the analysis of a multi-storey building, considering the effect of a masonry infill wall;

- To study the effect of shear wall and slabs on the response of a multi-storey framed structure;

- To investigate the effect of a wall opening on the response of a multi-storey frame-shear wall system structure;

- To investigate the influence of staircases on the behaviour of the multi-storey frame structure.

\section{Structural model}

Due to computational complexity and time-consuming nature of analysing shear walls and slabs, the analytical method is almost impossible without any assumptions, approximations and simplifications. As for the experimental method, it involves prohibitively high expenses and material wastages, thus not economically feasible in real-world engineering design. Therefore, the finite element analysis is applied in this study, with the help of sophisticated engineering software and modern high-end workstation.

\subsection{Finite element modelling}

For each research objective, several multi-storey building structures with the same plan view configuration have been modelled and analysed in ETABS. However, these modelling cases might be different in terms of the number of storeys and/or type of modelling concept applied. All the modelling cases are done in three dimensional instead of two dimensional, to obtain a more accurate analysis result. The material properties and the sectional properties for structural elements are standardised/made consistent in this research. Relevant analysis results are then presented in figures and tables for an easy comparison. A total of 61 modelling cases have been analysed in this study.

\subsection{Configurations of building components}

Out of 61 models in this research, which studied the effect of shear walls, slabs, wall openings and a masonry wall, 56 have the same plan view as the basis for comparison. The common plan view of these 56 modelling cases is shown in Figure 1. In this illustration, the thin line indicates concrete beams, whereas the thicker line indicates shear walls. The smallest square at the intersection of the gridlines indicates concrete columns. The lift core is placed at the very centre of the plan view of the modelled building.

This simple and symmetrical plan view has been adopted, such that the analysis result in this research is not affected by uncertainties or factors such as a complex building shape. As such, the analysis results of the modelling can be interpreted more readily. The modelled multi-storey building structure is symmetrical about both $x$-axis and $y$-axis, with the total planned area of $42 \times 42 \mathrm{~m}$.

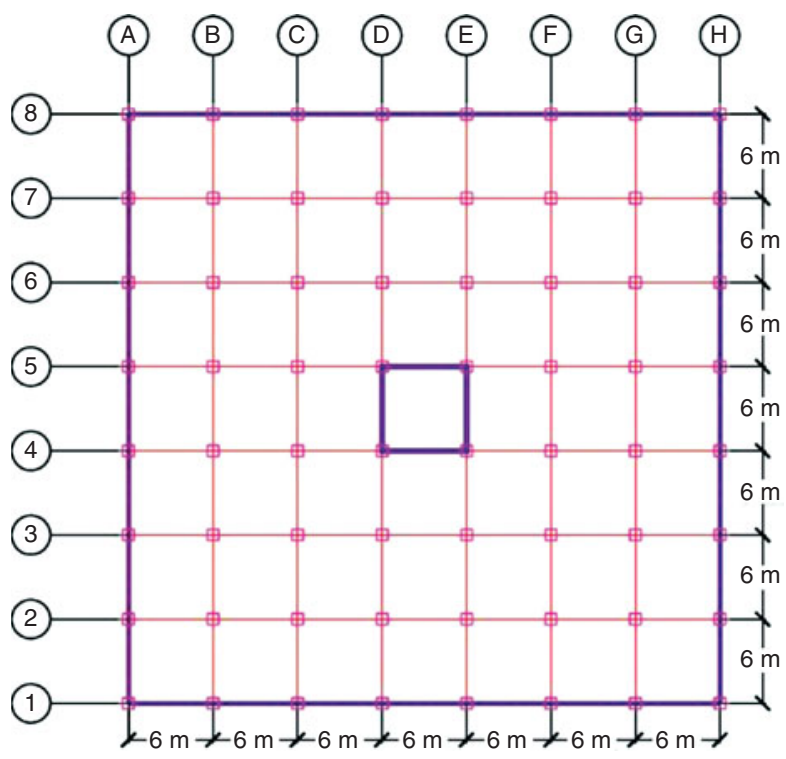

Fig. 1. Common plan view for modelling of multi-storey buildings 
Table 1. Modelling and design information summary

\begin{tabular}{l|l}
\hline Parameter & \multicolumn{1}{|c}{ Rating } \\
\hline Plan area & $42 \times 42 \mathrm{~m}$ \\
\hline Storey height & $3 \mathrm{~m}$ \\
\hline Beams & Concrete C40; 400×600 mm \\
\hline Columns & Concrete C40;800×800 mm \\
\hline Slab & Concrete C40; 120-mm thick \\
\hline Exterior wall & Concrete C40; 200-mm thick \\
\hline & Brick masonry wall; \\
\hline Lift core wall & 203.2-mm (8-in.) thick \\
\hline & Concrete C60; 250-mm thick \\
\hline
\end{tabular}

The dimension of each panel is $6 \times 6 \mathrm{~m}$, as all beams are $6 \mathrm{~m}$ in span length, supported by columns. Thus, columnto-column distance is only $6 \mathrm{~m}$. Each storey is $3-\mathrm{m} \mathrm{high}$, throughout the multi-storey building. The sectional properties of the structural elements are standardised as mentioned in Table 1. It is noted that a shear wall is considered as a concrete wall except for cases when masonry is mentioned.

A shell element is used to model the shear wall and slab in ETABS, to take into consideration both in-plane membrane stiffness and out-of-plane plate bending stiffness of the section. Any unmeshed shell element has an unrealistically high stiffness. Thus, the shear walls and slabs in the modelling are meshed into finer elements in order to improve the accuracy of the simulation result, and better reflect the actual behaviour of a real structure. The major trade-off, however, is the increase in the analysis time taken by the programme. Thus, the mesh size of the element used is compromised between the computational time and accuracy.

The common plan view for the remaining five modelling cases with staircase is similar to that without a

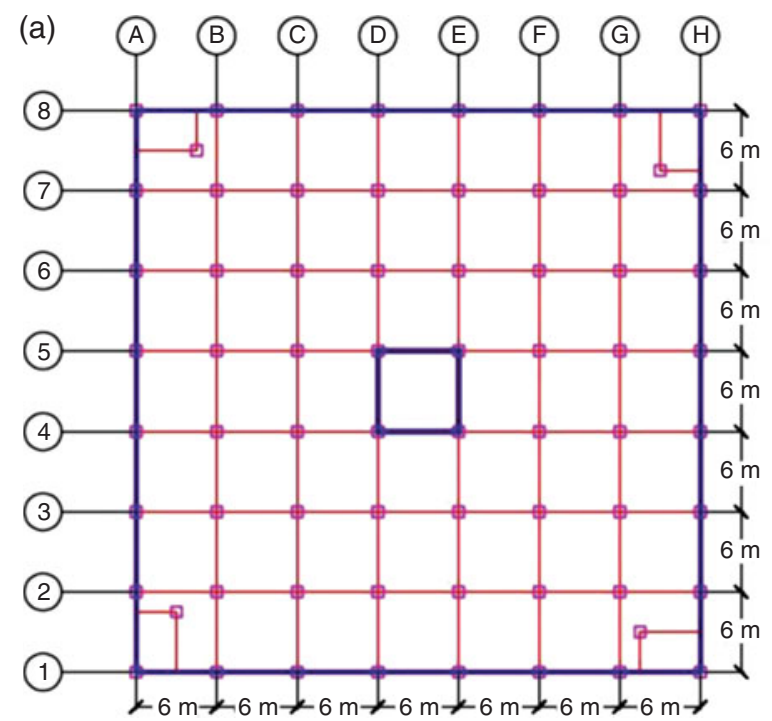

staircase, only with a slight modification to accommodate the staircases. Panel dimension, storey height, standardised sectional properties of structural elements, etc. remain the same. The common plan view for modelling with staircase is as shown in Figure 2a. To better illustrate the modelling detail, three-dimensional view for a 5 -storey building structure modelling is shown in Figure 2b.

In the modelling, there are openings on the slab $(3.0 \times 4.5 \mathrm{~m})$ to accommodate the staircase. This, however, might greatly reduce the stiffness as well as the stability of the multi-storey building structure. Hence, in order to maintain the structural stability, some beams and columns have been added at the edge and corner of a slab opening, respectively, while supporting the staircase at the same time. Some additional beams are added at each mid-storey height to partially support the span of the staircase.

\section{Finite element formulation}

Based on Newton's Second Law of Motion and D'Alembert's Principle (Fraser 1985) of Dynamic Equilibrium, the equation of motion governing the deformation or displacement $u(t)$ of the idealised MDF (Multi-Degree-ofFreedom) system structure, assuming to be linearly elastic and subjected to an external dynamic force, $\boldsymbol{p}(t)$, is given by the following matrix equation:

$$
\boldsymbol{m} \ddot{\boldsymbol{u}}+\boldsymbol{c} \dot{\boldsymbol{u}}+\boldsymbol{k} \boldsymbol{u}=\boldsymbol{p}(t),
$$

where: the term $\boldsymbol{m}$ is mass matrix of the structure; $\boldsymbol{c}$ is the damping matrix of the structure; $\boldsymbol{k}$ is the stiffness matrix of the structure; $\boldsymbol{u}$ is the displacement matrix; $\dot{\boldsymbol{u}}$ is the velocity matrix and $\ddot{\boldsymbol{u}}$ is the acceleration matrix:

The problem with free vibration requires that the external dynamic force, $\boldsymbol{p}(t)$, to be zero. In addition, for systems without damping, the damping matrix, $\boldsymbol{c}$, is also zero. Thus, by substituting $\boldsymbol{p}(t)=0$ and $\boldsymbol{c}=0$ into Eqn (1), the matrix equation governing the free vibration of linear

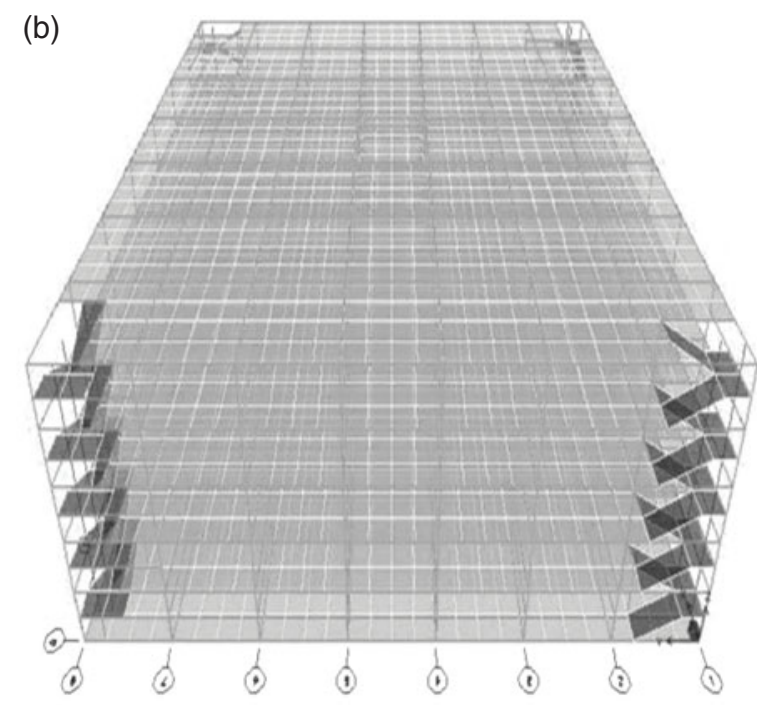

Fig. 2. Model of multi-storey buildings with staircase: (a) plan view and (b) three-dimensional view 
MDF systems becomes:

$$
m \ddot{u}+k u=0 .
$$

The free vibration of an undamped system of its natural vibration modes for a MDF system can be described mathematically by:

$$
\boldsymbol{u}(\boldsymbol{t})=\boldsymbol{q}_{\boldsymbol{n}}(\boldsymbol{t}) \varphi_{\boldsymbol{n}},
$$

where: $q_{n}(t)$ is the time variation of the displacements; $\varphi_{n}$ is the deflected shape, which does not vary with time. The time variation of the displacements; $q_{n}(t)$ can be described by the following simple harmonic function:

$$
\boldsymbol{q}_{\boldsymbol{n}}(\boldsymbol{t})=\boldsymbol{A}_{n} \cos \omega_{n} \boldsymbol{t}+\boldsymbol{B}_{n} \sin \omega_{n} \boldsymbol{t}
$$

$A_{n}$ and $B_{n}$ are the constant of integration that can be determined mathematically based on the initial conditions of motion. Substituting Eqn (4) with Eqn (3) leads to subsequent equations, in which the natural circular frequency, $\omega_{n}$, and deflected shape, $\phi_{n}$, are unknown.

Displacement matrix:

$$
\left(\boldsymbol{u}(\boldsymbol{t})=\varphi_{n}\left(\boldsymbol{A}_{n} \cos \omega_{n} \boldsymbol{t}+\boldsymbol{B}_{n} \sin \omega_{n} \boldsymbol{t}\right)\right) .
$$

Velocity matrix:

$$
\dot{\boldsymbol{u}}=\varphi_{\boldsymbol{n}}\left(-\omega_{n} \boldsymbol{A}_{\boldsymbol{n}} \sin \omega_{n} \boldsymbol{t}+\omega_{n} \boldsymbol{B}_{\boldsymbol{n}} \cos \omega_{n} \boldsymbol{t}\right) .
$$

Acceleration matrix:

$$
\ddot{\boldsymbol{u}}=\varphi_{n}\left(-\omega_{n}^{2} A_{n} \cos \omega_{n} t-\omega_{n}^{2} B_{n} \sin \omega_{n} t\right) .
$$

Simplifying the acceleration matrix $\ddot{\boldsymbol{u}}$ gives

$$
\ddot{\boldsymbol{u}}=\omega_{n}^{2} \varphi_{n}\left(A_{n} \cos \omega_{n} t-B_{n} \sin \omega_{n} t\right) .
$$

This is similar to:

$$
\ddot{u}=-\omega_{n}^{2} q_{n} \varphi_{n} .
$$

Therefore, the matrix equation (Eqn 2) for free vibration of linear MDF systems leads to:

$$
\left[-\omega_{n}^{2} \boldsymbol{m} \varphi_{n}+k \varphi_{n}\right] q_{n}(t)=\mathbf{0} .
$$

The following algebraic equation meets the solution, which is named as matrix eigenvalue problem. Since the stiffness and mass matrices $\boldsymbol{k}$ and $\boldsymbol{m}$ are known, the scalar eigenvalue $\omega_{n}^{2}$ and the eigenvectors or mode shapes $\varphi_{n}$ are determined:

$$
\boldsymbol{k} \varphi_{n}=\omega_{n}^{2} \boldsymbol{m} \varphi_{n} .
$$

To indicate the formal solution to Eqn (11), it is rewritten as:

$$
\left[\boldsymbol{k}-\omega_{n}^{2} \boldsymbol{m}\right] \varphi_{n}=0 .
$$

This can be interpreted as a set of $N$ homogenous algebraic equations for the $N$ elements $\phi_{j n}(j=1,2, \ldots, N)$. Reasonable solution of the equation leads to:

$$
\operatorname{det}\left[\boldsymbol{k}-\omega_{n}^{2} \boldsymbol{m}\right]=0 .
$$

When the determinant is expanded, a polynomial of order $N$ in $\omega_{n}^{2}$ is obtained. The vibrating system with $N$
DOFs contains $N$ natural frequencies $\omega_{n}(n=1,2, \ldots, N)$ corresponding natural periods, $T_{n}$; and natural modes $\phi_{n}$. Each of these vibration properties is natural or intrinsic property of the structure in free vibration, which is loadindependent, but depends only on its mass and stiffness properties.

\section{Numerical study}

All of the 61 models have been configured as per the materials and load assignment discussed in subsequent sections. Equivalent static analysis has been performed for all the configurations. The maximum roof displacement induced by wind loading has been thus determined as well. Besides the equivalent static analysis, the free vibration analysis is carried out for every individual model. The free vibration analysis is used to determine the undamped free vibration mode shapes and natural frequencies of a structure. The natural periods of the structure are determined from the free vibration analysis. Natural frequency $\left(f_{n}\right)$, which is the reciprocal of the natural period $\left(T_{n}\right)$, can thus be calculated. All the obtained results are then evaluated to see the optimal structural modelling.

\subsection{Material properties}

Except for brick masonry wall in some modelling, almost all structures in this research have been modelled as an $\mathrm{RC}$ building. The general concrete properties applied in modelling include density $(\rho)$ of $2447 \mathrm{~kg} / \mathrm{m}^{3}$ or selfweight (SW) of $24 \mathrm{kN} / \mathrm{m}^{3}$ and Poisson's ratio $(v)$ of 0.2 . Two types of concrete have been used in the modelling, that is, concrete $\mathrm{C} 40$ and concrete C60. The overall compressive strength of a masonry wall depends on the compressive strength of the individual masonry units and the type of mortar used, besides the quality of workmanship. In this study, it is assumed that type S mortar and clay masonry units with compressive strength of $4400 \mathrm{psi}$ (or $30.3 \mathrm{~N} / \mathrm{mm}^{2}$ ) are used for the modelled brick masonry wall. Thus, the net area compressive strength $\left(f_{c u}\right)$ of the masonry shall be $1500 \mathrm{psi}$, that is, equivalent to $10.3 \mathrm{~N} / \mathrm{mm}^{2}$. For convenient allusion, information on all material properties is summarised in Table 2.

\subsection{Load assigned}

The structural modelling includes dead load (DL) or SW of the building in consideration. At the same time, the occupancy of the modelled building is assumed to be general office, with live load (LL) of $2.5 \mathrm{kN} / \mathrm{m}^{2}$, which is in accordance with Table 1 in British Standards Institution (1996).

Moreover, in cases where staircases are being considered in the modelling and analysis, the LL applied on the staircase is $4.0 \mathrm{kN} / \mathrm{m}^{2}$. It is logical that the design LL applied on the staircase is higher as compared to that of the office area, because there is a probability that a staircase may be crowded with people in emergency cases. 
Table 2. Material properties summary

\begin{tabular}{l|l}
\hline Materials & \multicolumn{1}{|c}{ Properties } \\
\cline { 2 - 2 } Concrete C40 & $f_{c u}=40 \mathrm{~N} / \mathrm{mm}^{2}$ \\
\cline { 2 - 2 } & $E=28 \mathrm{GPa}$ \\
\cline { 2 - 2 } & $\rho=2447 \mathrm{~kg} / \mathrm{m}^{3}$ \\
\cline { 2 - 2 } Concrete C60 & Poisson's ratio, $v=0.2$ \\
\hline \multirow{5}{*}{ Brick masonry wall } & $f_{c u}=60 \mathrm{~N} / \mathrm{mm}^{2}$ \\
\cline { 2 - 2 } & $E=32 \mathrm{GPa}$ \\
\cline { 2 - 2 } & $\rho=2447 \mathrm{~kg} / \mathrm{m}^{3}$ \\
\cline { 2 - 2 } & $\mathrm{SW}=24 \mathrm{kN} / \mathrm{m}^{3}$ \\
\cline { 2 - 2 } & Poisson's ratio, $v=0.2$ \\
\hline \multirow{5}{*}{ Steel reinforcement } & $f_{y}=460 \mathrm{~N} / \mathrm{mm}^{2}$ \\
\hline & $f_{c u}=10.3 \mathrm{~N} / \mathrm{mm}^{2}$ \\
\cline { 2 - 2 } & $E=2.10 \mathrm{GPa}$ \\
\cline { 2 - 2 } & $\rho=2000 \mathrm{~kg} / \mathrm{m}^{3}$ \\
\cline { 2 - 2 } & $\mathrm{SW}=19.6 \mathrm{kN} / \mathrm{m}^{3}$ \\
\cline { 2 - 2 } & Poisson's ratio, $v=0.13$ \\
\hline & \\
\hline
\end{tabular}

\subsection{Equivalent static analysis}

Based on the provision in design standards, equivalent static analysis, which may also be known as the quasistatic analysis, is used for applying the wind load. The main concept of this analysis is that the kinetic energy of the wind is converted into an equivalent static pressure, which is then treated in a manner similar to that for a distributed gravity load. The major advantage of this analysis is its simplicity, by using modification factors to account for the dynamic effects. Wind load parameters, to be inputted into the program for generating wind load, are determined with reference to British Standards Institution (1997). The maximum roof displacement induced by wind loading, can thus be determined as well.

The effective wind speed, $V_{e}$ (in $\mathrm{m} / \mathrm{s}$ ), depends on several factors, such as the basic wind speed $\left(V_{b}\right)$, the altitude factor $\left(S_{a}\right)$, the direction factor $\left(S_{d}\right)$, the seasonal factor $\left(S_{s}\right)$, the probability factor $\left(S_{p}\right)$, and the terrain and building factor $\left(S_{b}\right)$, as shown in the following equations (British Standards Institution 1997):

$$
\begin{gathered}
\text { Site wind speed, } V_{s}=V_{b} \times S_{a} \times S_{d} \times S_{s} \times S_{p} \text {; } \\
\text { Effective wind speed, } V_{e}=V_{s} \times S_{b} .
\end{gathered}
$$

For all modelling, the basic wind speed, $V_{b}$ of $33 \mathrm{~m} / \mathrm{s}$ has been assumed. The altitude of the site is assumed to be the same as the mean sea level; thus, the altitude factor, $S_{a}$, is 1.0. Assuming that the orientation of the building is unknown or ignored, the direction factor, $S_{d}$, is 1.0. Also, the multi-storey building is assumed to be permanent and is exposed to the wind for a continuous period of more than 6 months; therefore, the seasonal factor, $S_{s}$, is 1.0.

Since the modelled building is for normal design application, the probability factor $S_{p}$ is 1.0 as well. The terrain and building factor $\left(S_{b}\right)$ shall be determined based on the assumptions that the location of the multi-storey building in modelling is in a town area, and the closest distance to a sea is greater than $100 \mathrm{~km}$. Just as additional information, it will be shown how the effective wind speed $V_{e}$ is related to the dynamic wind pressure. The dynamic pressure $q_{s}$ (in $\mathrm{Pa}$ ) and the effective wind speed $V_{e}$ (in $\mathrm{m} / \mathrm{s}$ ) are related as described in the following equation:

$$
\text { Dynamic pressure, } q_{s}=0.613 V_{e}^{2} \text {. }
$$

This dynamic pressure will act on the surface of the multi-storey building. The overall wind load exerted on the multi-storey building is given as follows:

The overall horizontal loads,

$$
P=0.85\left(P_{\text {front }}-P_{\text {rear }}\right)\left(1+C_{r}\right) .
$$

The factor 0.85 accounts for the non-simultaneous action between the front and rear faces. $P_{\text {front }}$ is the horizontal component of the surface load summed over the windward-facing shear walls and roofs. $P_{\text {rear }}$ is the horizontal component of the surface load summed over the leeward-facing shear walls and roofs. Besides the effective wind speed, the main parameters to be inputted in program are the dynamic augmentation factor, $C_{r}$, and size effect factor, $C_{a}$. The factor, $C r$, depends on the building type factor, $K_{b}$ as well as the actual height of the building above ground, $H$. The size effect factor, $C_{a}$, depends on site exposure and the diagonal dimension.

\subsection{Free vibration analysis}

Besides the equivalent static analysis, the free vibration analysis has been performed. The free vibration analysis, which is also known as eigenvector analysis, is used to determine the undamped free vibration mode shapes and natural frequencies of a structure, which provide an excellent insight into the behaviour of the structure (Computers and Structures Inc. 1995). This is due to the fact that natural frequency is load-independent; it only depends on the mass and stiffness of the structure. Each structural member (e.g. beam, column, shear walls and slab) of the actual building structure contributes to the inertial (mass) property, elastic (stiffness) property, and energy dissipation (damping) property of the building structure. However, in the idealised system, each of these properties is categorised into three separate pure components, that is, mass component, stiffness component and damping component.

Free vibration is initiated by disturbing the structure from its equilibrium position by some initial displacements and/or by imparting some initial velocities. In the present analysis, natural periods and mode shapes are the outputs of the free vibration analysis. The fundamental period (or natural period), $T_{n}$, of a building depends on the distribution of stiffness and mass along its height (Kose 2009). Thus, the stiffness of the structure model is evaluated based on its correlation of fundamental frequency and the maximum roof displacement. 


\section{Results and discussion}

Natural frequency and lateral deformation are important parameters in calculating the base shear and the base overturning moment for structural element design. Thus, the maximum roof displacement and natural frequency are used in evaluating the structural performance under dynamic loadings.

For evaluating the effect of different modelling concepts of the same multi-storey building structure, the analysis results are presented in terms of the maximum roof displacement $D_{\text {roof }}(\mathrm{mm}), \Delta D_{\text {roof }}(\%)$, natural frequency $f_{n}(\mathrm{~Hz})$ and $\Delta f_{n}(\%) . \Delta D_{\text {roof }}(\%)$ indicates the percentage reduction of the maximum roof displacement based on that of the frame structure modelling. $\Delta f_{n}(\%)$ indicates the percentage increment of natural frequency based on that of the frame structure modelling.

In most structural design under lateral loadings, it is desirable to limit/ minimise the lateral deformation or increase the lateral stiffness of the structure, within optimum construction cost. Thus, the percentage reduction of the maximum roof displacement $\left(\Delta D_{\text {roof }}\right)$ and the percentage increment of the natural frequency $\left(\Delta f_{n}\right)$ are used to assess the improvement on structural performance of other types of modelling in comparison to that of the frame structure modelling.

Intrinsically, the effect of considering particular structural elements or details (e.g. shear walls, slabs, wall openings, staircases, etc.) in modelling can be studied by the comparison of the relevant plotted figures.

\subsection{Effect of wall openings}

In addition to the 'frame' and 'frame + shear wall' modelling with $20 \%$ shear wall opening, 'frame + shear wall + slab' modelling with $20 \%$ shear wall opening has been performed and analysed. '20\% O' shown in the following figures in this section indicates $20 \%$ shear wall opening. $20 \%$ shear wall opening, in fact, means that $20 \%$ area of each shear walls refers to the openings (e.g. windows), to more accurately reflect the real multistorey building structure.

Figure 3 gives a general overview of the maximum roof displacement for those 5 modelling concepts. It can be observed that the maximum roof displacement increases as the number of storeys increases. For higher multi-storey building structure, the 'frame + shear wall' modelling and 'frame + shear wall + slab' modelling, with and without openings, have significantly less of the maximum roof displacement, as compared to that of the 'frame' modelling. The percentage reduction in the maximum roof displacement (over that of the conventional frame structure modelling) for 'frame + shear wall' modelling and 'frame + shear wall + slab' modelling is shown in Figures 4 and 5, respectively.

Through Figure 4 for 'frame + shear wall' modelling, the higher percentage reduction of maximum roof displacement indicates higher lateral stiffness of the structure. From observation, the effect of shear wall opening becomes increasingly important for building structures higher than 15 storeys. This is shown by the

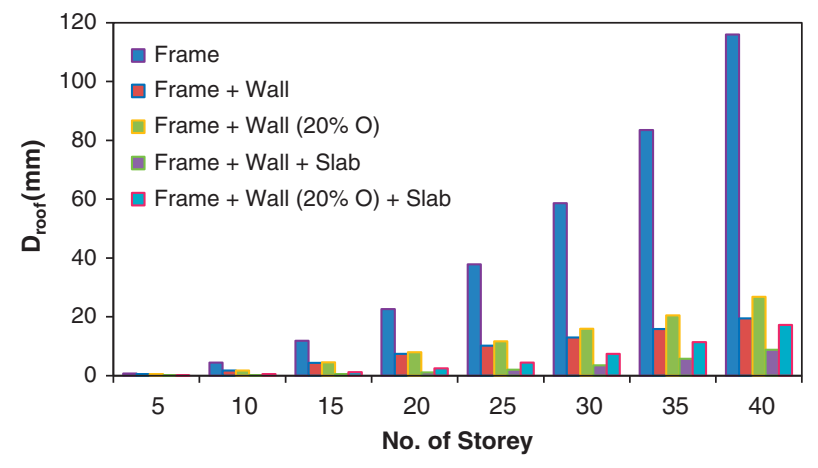

Fig. 3. Effect of wall opening on roof displacement for varying configurations

'gap' between the figures of 'with openings' and 'without openings'. The 'gap' becomes increasingly larger as the number of storeys increases.

Also, the figure for 'with openings' is generally lower than that of 'without openings', indicating that all openings in 'frame + shear wall' structure resulted in a lower lateral stiffness of the building structure, as compared to those counterpart without openings. However, even with the presence of wall openings, the significance of considering shear walls in addition to the frame structure modelling increases as the number of storeys increases.

Based on Figure 5, the effect of a shear wall opening on the lateral stiffness of a multi-storey building is significant in all cases, with the exception of the 5-storey building. This is most probably due to round-up error since the maximum roof displacement value for 5-storey 'frame + shear wall + slab' modelling is very small.

Similar to the cases for 'frame + shear wall' modelling, the wall openings tend to reduce the lateral stiffness of the structure, thus allowing a greater maximum roof displacement. However, the effect of wall openings is more pronounced in the cases of 'frame + shear wall + slab' modelling. This is shown by the figure of percentage for 'with openings' is much lower than that for 'without openings'.

By observing the general trend in Figure 6, the mode 1 natural frequency (or fundamental frequency) for the 'frame + shear wall + slab' modelling without opening is the highest, followed by the 'frame + shear wall + slab'

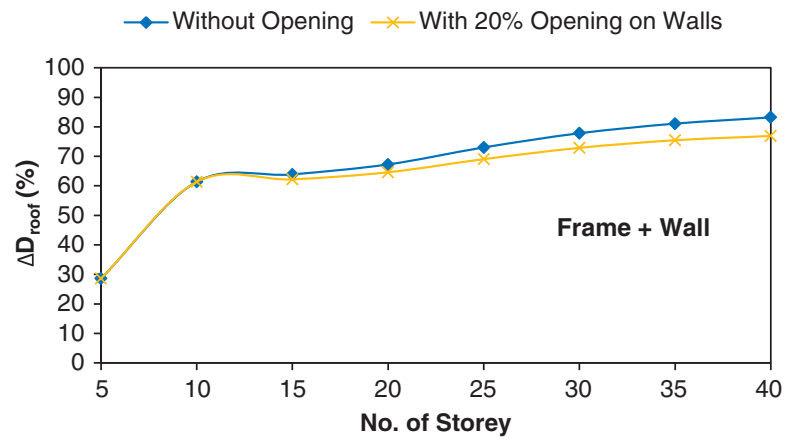

Fig. 4. Roof displacement increment, $\Delta D_{\text {roof, }}$ in effect of wall openings 


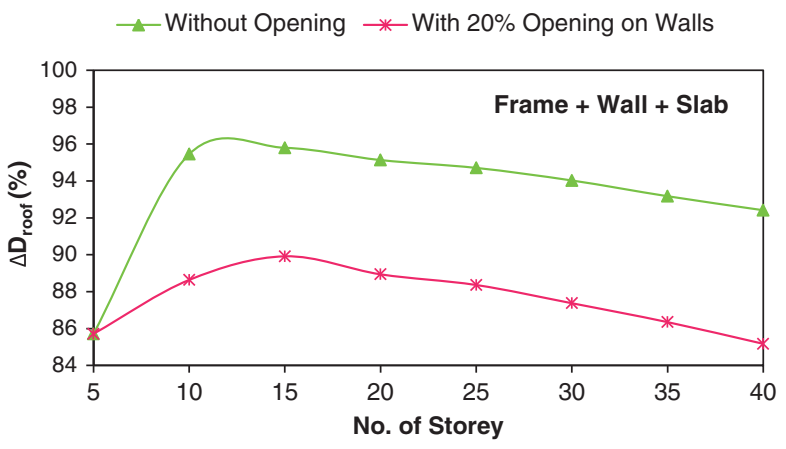

Fig. 5. Increment of roof displacement, $\Delta D_{\text {roof }}$, in effect of wall openings and slabs

modelling with $20 \%$ opening, then 'frame + shear wall' modelling without opening, 'frame + shear wall' modelling with $20 \%$ opening and, lastly, the 'frame' modelling. This indirectly implies that 'frame' modelling has the lowest lateral stiffness, while the 'frame + shear wall + slab' modelling without an opening has the highest lateral stiffness.

The difference between 'frame + shear wall' modelling, with and without openings, is quite close together as compared to that for the 'frame + shear wall + slab' modelling, with and without opening. This indicates that the effect of a shear wall opening is more pronounced in the cases of 'frame + shear wall + slab' modelling.

In addition, it can be observed that fundamental frequencies for all types of modelling concepts decrease as the number of storey increases. In other words, higher buildings have lower fundamental frequencies and vice versa. The percentage increment of fundamental frequency for 'frame + shear wall' modelling. The percentage increment in fundamental frequency for the modelling with $20 \%$ opening ranges from 36.8 to $134.9 \%$ (from a 5 -storey building to a 40 -storey building), whereas that for the modelling without a shear wall opening ranges from 36.7 to $178.6 \%$ (from a 5 -storey building to a 40 -storey building). The maximum difference in the percentage is $43.7 \%$, in the case of 40 -storey buildings. For a 15 -storey building and lower, the difference in the percentage is less than $3.0 \%$.

The effect of wall openings becomes increasingly significant, especially for building structures higher than 15 storeys. In other words, the significance of considering

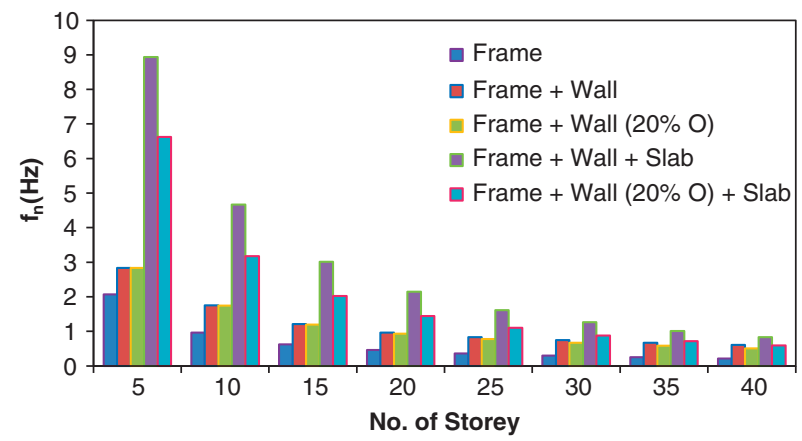

Fig. 6. Natural frequency, $f_{n}$, considering wall openings wall openings increases as the number of storey increases. This matches well with the result for percentage reduction of the maximum roof displacement in Figure 4. The effect of a shear wall opening is significant for 'frame + shear wall + slab' modelling, regardless of the number of storeys in a building. The percentage increment in the fundamental frequency for the modelling with $20 \%$ opening ranges from 173.4 to $229.5 \%$, whereas that for the modelling without opening ranges from 280.5 to $383.8 \%$. The minimum difference in the percentage is $107.1 \%$, in the case of 40 -storey buildings, whereas the maximum difference in the percentage is $159.1 \%$, in the case of 15 -storey buildings.

\subsection{Effect of a masonry wall}

In this part of the research, brick masonry is used to model the exterior shear wall, instead of the RC with $\mathrm{C} 40$ concrete. However, the lift core shear wall is still being modelled as an RC shear wall with C60 concrete. In the following figures, the 'shear wall' refers to the $\mathrm{RC}$ exterior shear wall, whereas the 'masonry shear wall' refers to the brick masonry exterior shear wall. The 'frame' modelling and 'frame + shear wall' modelling are shown in figures for the purpose of comparison only.

By observing Figure 7, it is found that, for all modelling concepts, the maximum roof displacement increases as the building height increases. Also, for the same building height, the 'frame' modelling has the highest maximum roof displacement followed by the 'frame + masonry wall', while the 'frame + shear wall' modelling has comparatively the lowest maximum roof displacement. Based on Figure 8, the effect of the brick masonry wall is compared with that of the RC shear wall.

From Figure 8, the figures for the percentage reduction in the maximum roof displacement for "frame + shear wall' modelling and 'frame + masonry wall' modelling have a similar trend, that is, the effect of considering the shear walls is, in general, more significant for higher buildings. It is also observed that the brick masonry wall provides less structural stiffness to the building as compared to that of the RC shear wall. This may be due to the fact that brick masonry and RC not only differ in terms of material type, but also their compressive strengths. The $\mathrm{C} 40 \mathrm{RC}$ has the compressive strength of

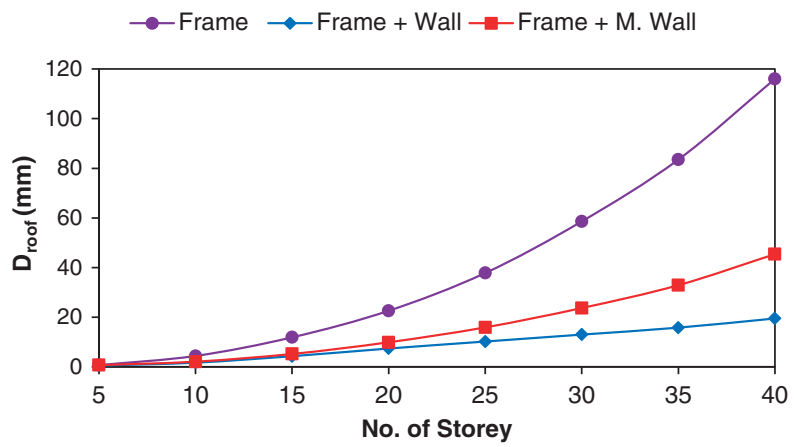

Fig. 7. Behaviour of roof displacement, $D_{\text {roof }}$, considering masonry walls 


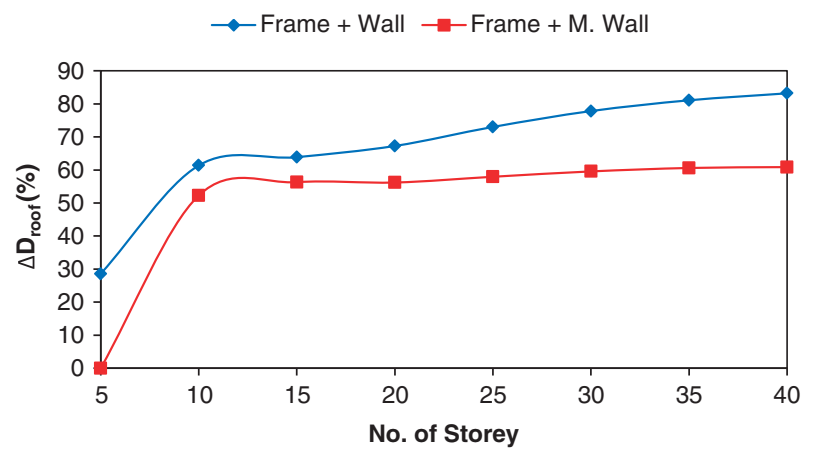

Fig. 8. Increment of roof displacement, $\Delta D_{\text {roof }}$, in effect of masonry walls

$40 \mathrm{~N} / \mathrm{mm}^{2}$, whereas the brick masonry only has the compressive strength of $10.3 \mathrm{~N} / \mathrm{mm}^{2}$.

With reference to Figure 9, all modelling concepts have decreasing fundamental frequencies as the number of storey increases. This is because the lower buildings are generally stiffer than their higher buildings counterpart. For the same building height, the 'frame' modelling has the lowest fundamental frequency, followed by the 'frame + masonry wall' modelling, while the 'frame + shear wall' modelling has the highest fundamental frequency.

From Figure 10, the significance of considering RC shear wall on a multi-storey building increases as the number of storeys increases (36.7-178.6\%), as discussed in earlier sections. As for the masonry wall, the percentage increment in fundamental frequency is around 71.2$77.6 \%$, with the exception of the 5-storey building (33.1\%). The difference in structural performance of these two modelling concepts increases as the number of storeys increases; this is shown by the 'gap' between the figures.

The similar trend of figures allows for the same figure interpretation and deduction. Although mode 1 and mode 2 natural frequencies are, in general, the same, but the mode shape is different. The corresponding natural frequencies in the second higher mode have been illustrated in Table 3. This is most probably due to the symmetrical arrangement of the building's plan view.

For higher modes, natural frequencies for the 'frame + masonry wall' modelling decrease as the number of storeys increases. However, this decrement is not as obvious as that of the lower modes. The mode 4 natural frequencies decrease from $2.8082 \mathrm{~Hz}$ (5-storey building) to $0.9252 \mathrm{~Hz}$ (40-storey building). The percentage

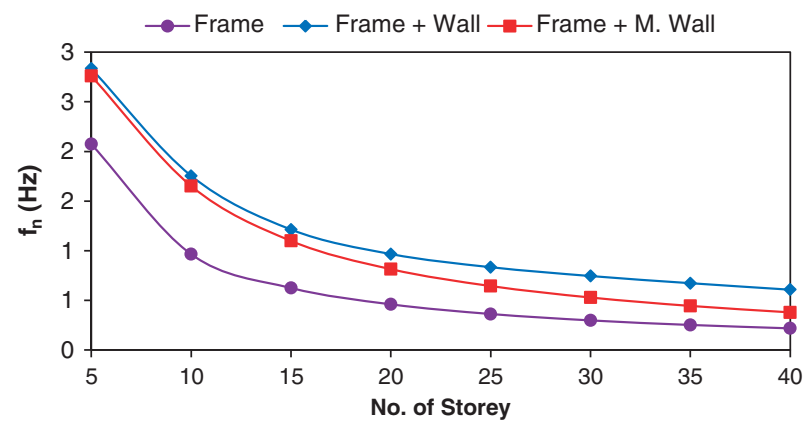

Fig. 9. Natural frequency, $f_{n}$, for masonry walls inclusion

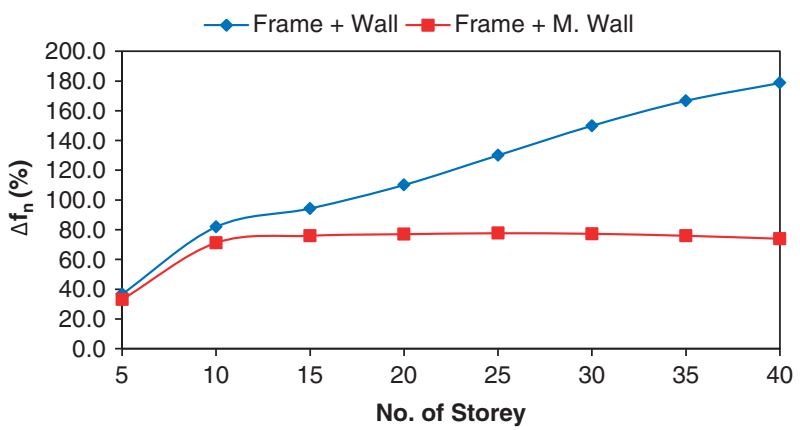

Fig. 10. Increment of natural frequency, $\Delta f_{n}$, for masonry walls inclusion

increment in higher modes natural frequency for 'frame + masonry wall' modelling is no longer dependent on the building height. It is observed that the effect of the brick masonry wall is most significant for a 10 -storey building, and least significant for a 30 -storey building.

By and large, it is observed that the consideration of a brick masonry wall in addition to the conventional frame modelling is significant, especially for higher buildings. However, the lateral stiffness provided by the brick masonry wall is not as significant as compared to the $\mathrm{RC}$ shear wall.

\subsection{Effect of a staircase}

To investigate the effect of a staircase on the response of the multi-storey building, staircases have been added to the 'frame + shear wall + slab' modelling instead of the 'frame + shear wall' modelling. The logic behind this is due to the fact that slabs are much easier to be modelled as compared to a staircase; thus, it is most probable that a practicing engineer would model slabs even before considering a staircase.

In this research, there are slab openings to accommodate the staircase. To maintain structural stability at the slab opening as well as to support staircases, additional beams and columns have been added at an appropriate location. Theoretically, addition of structural elements such as staircases and additional beams and columns should result in a much higher lateral stiffness of the structure, thereby reducing the lateral deformation induced by lateral load (e.g. wind load and seismic load). However, at the same time, the presence of slab openings may reduce the stiffness of slab to a considerable degree. Thus, it is important to investigate the resultant effect of considering staircases in structural analysis.

Buildings of 5-, 10-, 20-, 30- and 40-storey were modelled with staircases. The results are shown in Figures 11-14. The 'frame' modelling, 'frame + shear wall' modelling and 'frame + shear wall + slab' are shown in figures for the purpose of comparison only.

Figure 11 shows that the maximum roof displacement increases as the number of storeys of a building increases. This applied to all modelling concepts above. Therefore, the same interpretation or deduction can be made. It is noted that the displacement variation for "frame + shear wall + slab + Stair' modelling and that of the 'frame + 
Table 3. Comparison of frequency considering masonry wall (second higher mode shape)

\begin{tabular}{|c|c|c|c|c|c|}
\hline \multicolumn{6}{|c|}{ Eigenvector analysis results for mode 2} \\
\hline \multirow[b]{2}{*}{ Number of storeys } & \multirow{2}{*}{$\begin{array}{l}\text { Frame } \\
f_{n}(\mathrm{~Hz})\end{array}$} & \multicolumn{2}{|c|}{ Frame + wall } & \multicolumn{2}{|c|}{ Frame + masonry wall } \\
\hline & & $f_{n}(\mathrm{~Hz})$ & $\Delta f_{n}(\%)$ & $f_{n}(\mathrm{~Hz})$ & $\Delta f_{n}(\%)$ \\
\hline 5 & 2.0730 & 2.8604 & 38.0 & 2.7886 & 34.5 \\
\hline 10 & 0.9646 & 1.7544 & 81.9 & 1.6513 & 71.2 \\
\hline 15 & 0.6246 & 1.2133 & 94.3 & 1.0988 & 75.9 \\
\hline 20 & 0.4600 & 0.9663 & 110.1 & 0.8141 & 77.0 \\
\hline 25 & 0.3626 & 0.8340 & 130.0 & 0.6441 & 77.6 \\
\hline 30 & 0.2982 & 0.7452 & 149.9 & 0.5286 & 77.2 \\
\hline 35 & 0.2524 & 0.6729 & 166.7 & 0.4440 & 75.9 \\
\hline 40 & 0.2180 & 0.6074 & 178.6 & 0.3792 & 73.9 \\
\hline
\end{tabular}

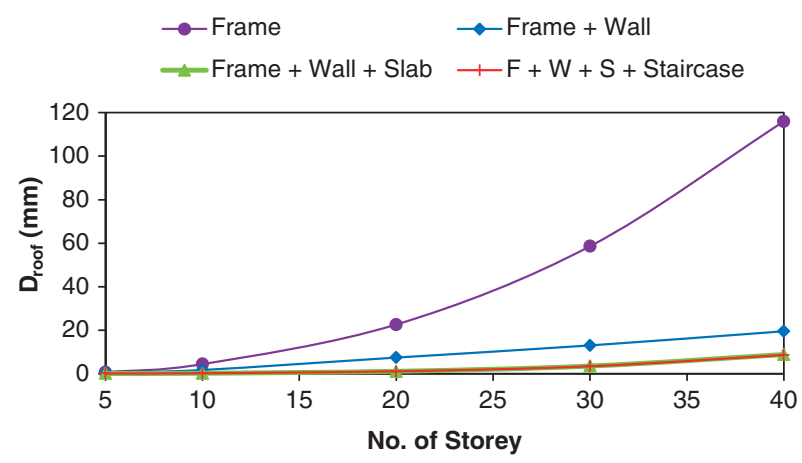

Fig. 11. Roof displacement, $D_{\text {roof, for different configurations }}$ compared to staircase inclusion

shear wall + slab' modelling are extremely close to each other, to the extent that both figures almost merge together (Figs 10-12). The maximum roof displacement for 'frame + shear wall + slab + Stair' modelling ranges from 0.1 to $8.6 \mathrm{~mm}$ (from a 5 -storey building to a 40 -storey building), whereas that for 'frame + shear wall + slab' modelling, it ranges from 0.1 to $8.8 \mathrm{~mm}$ (from a 5-storey building to 40-storey building) which are also mentioned in Table 4.

The percentage reduction in the maximum roof displacement for 'frame + shear wall + slab + Stair' modelling ranges from 85.7 to $92.6 \%$ (from a 5 -storey building to a 40 -storey building), whereas that for 'frame + shear wall + slab' modelling, it ranges from 85.7 to $92.4 \%$ (from a 5 -storey building to a 40 -storey building).

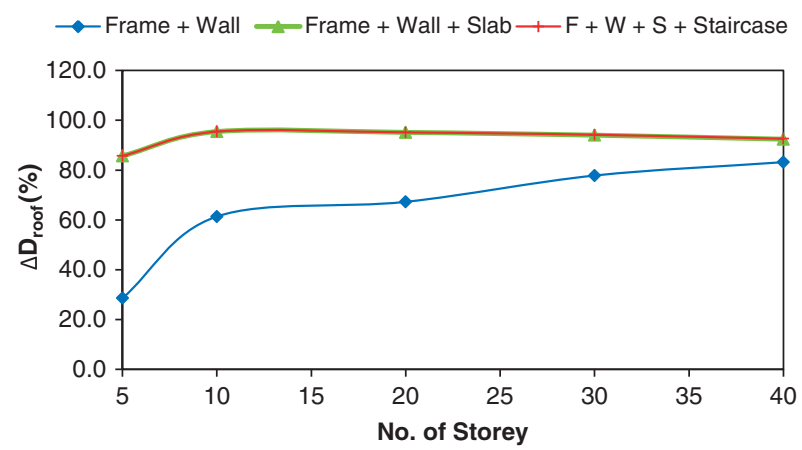

Fig. 12. Increment of roof displacement, $\Delta D_{\text {roof, }}$ comparing effect of staircase
This indicates that consideration of staircases with slab openings (which accommodate the staircases) in addition to the 'frame + shear wall + slab' modelling does not provide significant improvement on the lateral stiffness of a multi-storey building structure. It can thus be deduced that the additional lateral stiffness provided by the staircase is offset by the adverse effect of slab openings.

As the building height increases, all the patterns of the percentage reduction in the maximum roof displacement come closer together. This might lead to a prediction/hypothesis that for a 50 -storey building or higher, the consideration of slabs and a staircase does not provide much improvement in structural performance over the 'frame + shear wall' modelling.

The fundamental frequency decreases as the number of storeys increases, for all types of modelling (Figure 13). Also, the figure of 'frame + shear wall + slab + Stair' modelling is very slightly lower than that of the 'frame + shear wall + slab' modelling. The fundamental frequency for 'frame + shear wall + slab + Stair' modelling ranges from $8.8106 \mathrm{~Hz}$ (5-storey building) to $0.8204 \mathrm{~Hz}$ (40-storey building), whereas that for the 'frame + shear wall + slab' modelling, it ranges from $8.9366 \mathrm{~Hz}$ (5-storey building) to $0.8295 \mathrm{~Hz}$ (40-storey building). This indicates that the prior modelling is slightly less stiff as compared to the latter modelling.

The percentage increment in fundamental frequency for 'frame + shear wall + slab + Stair' modelling and that for the 'frame + shear wall + slab' modelling are extremely close to each other, where the former is very slightly lower than the latter. The percentage increment in fundamental frequency for 'frame + shear wall + slab + Stair' modelling ranges from $276.3 \%$ (40-storey building) to $376.0 \%$ (10-storey building), whereas that for the 'frame + shear wall + slab' modelling, it ranges from $280.5 \%$ (40-storey building) to $383.8 \%$ (10-storey building). This leads to the deduction that the adverse effect of a slab opening (to accommodate the staircase) is slightly more significant than the additional lateral stiffness provided by staircases.

The higher mode natural frequencies (Table 5) for 'frame + shear wall + slab + Stair' modelling range from 


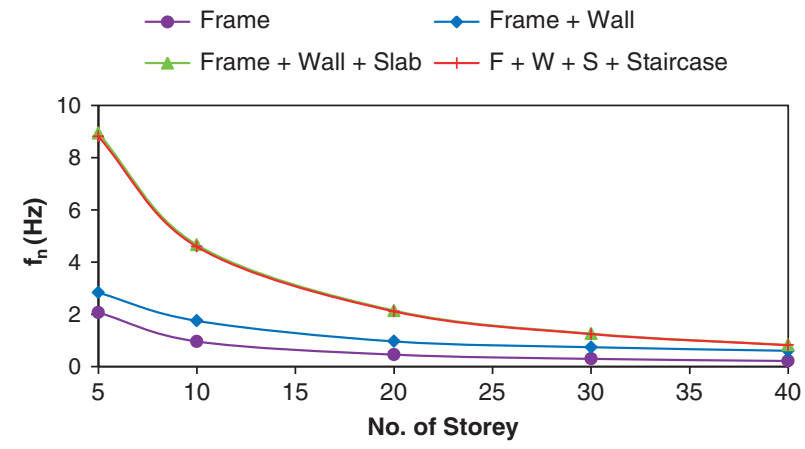

Fig. 13. Natural frequency, $f_{n}$, for different configurations compared to staircase inclusion

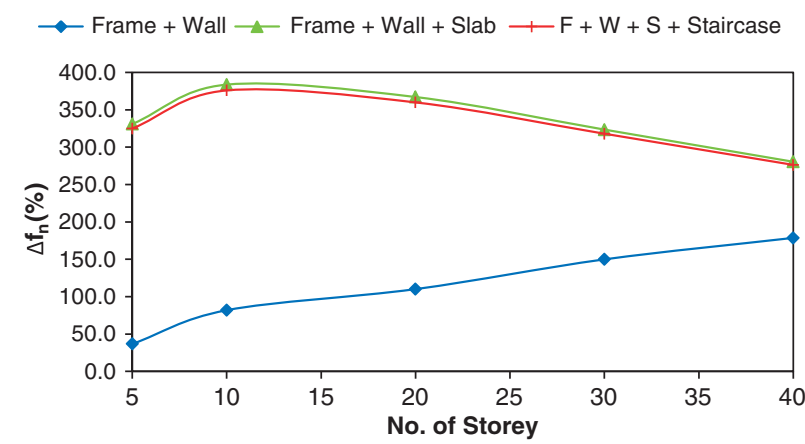

Fig. 14. Increment of natural frequency, $\Delta f_{n}$, considering effect of staircase

$12.7551 \mathrm{~Hz}$ (5-storey building) to $2.7716 \mathrm{~Hz}$ (40-storey building), whereas that for the 'frame + shear wall + slab' modelling, they range from $12.7551 \mathrm{~Hz}$ (5-storey building) to $2.8193 \mathrm{~Hz}$ (40-storey building).
It is perceived that both 'frame + shear wall + slab + Stair' modelling and 'frame + shear wall + slab' modelling have achieved the maximum percentage increment of the higher mode natural frequencies for a 10-storey building. For any building higher than a 10-storey building, the percentage increment of the higher mode natural frequencies starts to decrease.

\subsection{Assessment of outcomes}

It is common to have wall openings on multi-storey buildings. Based on the maximum roof displacement and fundamental frequency figures for 'frame + shear wall' modelling, it is observed that the effect of a shear wall opening becomes increasingly important for building structures higher than 15 storeys. However, even with the presence of wall openings, the significance of considering shear walls in addition to frame structure modelling increases as the number of storeys increases.

For the 'frame + shear wall' modelling, the trend of fundamental frequency increment is similar to that of the maximum roof displacement reduction, that is, the significance of considering shear wall in addition to the frame structure modelling increases as the number of storeys increases. This is not the case for the 'frame + slab' modelling and 'frame + shear wall + slab' modelling.

It has also been observed that the consideration of slabs alone in addition to the frame modelling may have negligible improvement on structural performance. However, when the slabs are combined with shear walls in addition to the frame structure modelling, the reduction in the maximum roof displacement and the increment in fundamental frequency are significant.

Table 4. Maximum roof displacement in static analysis

\begin{tabular}{l|c|c|c|c|c|c|c}
\hline \multirow{2}{*}{$\begin{array}{l}\text { Number of } \\
\text { storeys }\end{array}$} & Frame & \multicolumn{2}{|c|}{ Frame + wall } & \multicolumn{2}{c|}{ Frame + wall + slab } & \multicolumn{2}{c}{ Frame + wall + slab + staircase } \\
\cline { 2 - 9 } & $D_{\text {roof }}(\mathrm{mm})$ & $D_{\text {roof }}(\mathrm{mm})$ & $\Delta D(\%)$ & $D_{\text {roof }}(\mathrm{mm})$ & $\Delta D(\%)$ & $D_{\text {roof }}(\mathrm{mm})$ & $\Delta D(\%)$ \\
\hline 5 & 0.7 & 0.5 & 28.6 & 0.1 & 85.7 & 0.1 & 85.7 \\
\hline 10 & 4.4 & 1.7 & 61.4 & 0.2 & 95.5 & 0.2 & 95.5 \\
\hline 30 & 22.6 & 7.4 & 67.3 & 1.1 & 95.1 & 9.1 & 95.1 \\
\hline 40 & 58.6 & 13.0 & 77.8 & 3.5 & 94.0 & 3.4 & 94.2 \\
\hline
\end{tabular}

Table 5. Comparison of frequency considering staircase (second higher mode shape)

Eigenvector analysis results for mode 2

\begin{tabular}{l|c|c|c|c|c|c|c}
\hline \multirow{2}{*}{$\begin{array}{l}\text { Number of } \\
\text { storeys }\end{array}$} & Frame & \multicolumn{2}{|c|}{ Frame + wall } & \multicolumn{2}{c|}{ Frame + wall + slab } & \multicolumn{2}{c}{ Frame + wall + slab + staircase } \\
\cline { 2 - 8 } & $f_{n}(\mathrm{~Hz})$ & $f_{n}(\mathrm{~Hz})$ & $\Delta f_{n}(\%)$ & $f_{n}(\mathrm{~Hz})$ & $\Delta f_{n}(\%)$ & $f_{n}(\mathrm{~Hz})$ & $\Delta f_{n}(\%)$ \\
\hline 5 & 2.0730 & 2.8604 & 38.0 & 8.9366 & 331.1 & 8.8106 & 325.0 \\
\hline 10 & 0.9646 & 1.7544 & 81.9 & 4.6664 & 383.8 & 4.5914 & 376.0 \\
\hline 30 & 0.4600 & 0.9663 & 110.1 & 2.1487 & 367.1 & 2.1155 & 359.9 \\
\hline 40 & 0.2982 & 0.7452 & 149.9 & 1.2631 & 323.5 & 1.2467 & 318.1 \\
\hline
\end{tabular}


However, the effect of considering slab is more significant in higher modes, especially in the cases of lower buildings. Also, for higher modes, natural frequency in 'frame + shear wall' modelling, the significance of the shear wall is no longer dependent on the building height. In terms of percentage increment in natural frequency based on that of the 'frame' modelling, 'frame + shear wall + slab' modelling is generally performing much better than considering shear walls or slabs alone, throughout all modes.

For 'frame + shear wall + slab' modelling, the effect of shear wall opening on the lateral stiffness of a multistorey building is, in general, significant, regardless of the building height. Also, the effect of wall openings is more pronounced in the cases of 'frame + shear wall + slab' modelling, as compared to the 'frame + shear wall' modelling. Based on all observations, it is shown that wall openings do reduce the lateral stiffness of a multistorey building.

Brick masonry wall itself does possess some structural strength, whether it is being considered in the structural design or not. Generally, the effect of a brick masonry wall in addition to the conventional frame modelling is significant, especially for higher buildings. However, the lateral stiffness provided by the brick masonry wall is not as significant as compared to the RC shear wall.

In this study, staircases have been added in addition to the 'frame + shear wall + slab' modelling. Theoretically, the consideration of staircase in modelling and analysis result in a stiffer structure. However, when considering the staircase in the modelling, the lateral stiffness is slightly lower than that without a staircase. This is most probably due to the fact that the effect of a slab opening to accommodate the staircase is more significant than the additional stiffness provided by staircases, at least for the modelled structure in this study. Slab openings will adversely affect the lateral stiffness of the structure.

Thus, the 'frame + shear wall + slab' modelling needs to consider both wall openings and slab openings, in order to avoid the overestimation of the structural capacity, which is highly undesirable in structural design. Otherwise, a more conservative approach would be using just the 'frame + shear wall' modelling, which requires less computational resources. However, the trade-off would be overdesign, within an acceptable limit.

\section{Conclusions}

Besides the traditional deign strategy existence of a shear wall, wall openings, masonry wall and slab openings/ staircase have been incorporated in this study by means of numerous structural modelling. Meticulous reckoning on structural responses of dissimilarly configured high-rise buildings sorts out the succeeding conclusions:

1) Wall openings and slab openings, which would reduce the lateral stiffness of a structure, should be taken into the consideration in structural analysis and design, especially in the case of a highrise building, to prevent unsafe design;

2) For safety reasons, it is generally not recommended to model staircases in addition to "frame + shear wall + slab' modelling unless the effect of wall openings and slab openings are adequately considered in the analysis. This, however, might considerably increase the modelling effort as well as computational time;

3) If the strength and stiffness provided by shear walls and slabs are used for the advantage of structural design, there would be no additional cost incurred. Yet, it is even possible to come up with an effective and more economical design;

4) By considering shear walls and slabs in the modelling and analysis, the structural elements of a multi-storey building, which are subjected to the lateral load, may experience a lower shear, moment and lateral deformation. Thus, the size of the structural member or the steel reinforcement could be reduced to save cost while satisfying the safety and serviceability requirement/provisions from the local design codes;

5) To better understand the effect of wall openings, which are common in multi-storey buildings, modelling with different percentage of wall openings can be performed, for example, with $5 \%$, $10 \%, 25 \%$ and $50 \%$ wall openings. Also, the effect of a shear wall opening location shall be investigated as well;

6) In this research, besides the free vibration analysis, only the equivalent static analysis has been performed. Static pushover analysis and response spectrum analysis could be performed to further investigate the response of a multi-storey building under seismic loading.

\section{Acknowledgement}

The authors would like to gratefully acknowledge the University of Malaya (UM), for their constant support through the grant RG140-12AET provided to fund the research work.

\section{References}

Balkaya, C.; Kalkan, E. 2003. Nonlinear seismic response evaluation of tunnel form building structures, Computers and Structures 81(3): 153-165. http://dx.doi.org/10.1016/S0045-7949(02)00434-0

Balkaya, C.; Kalkan, E. 2004. Seismic vulnerability, behavior and design of tunnel form building structures, Engineering Structures 26(14): 2081-2099. http://dx.doi.org/10.1016/j.engstruct.2004.07.005

Borzi, B.; Pinho, R.; Crowley, H. 2008. Simplified pushoverbased vulnerability analysis for large-scale assessment of RC buildings, Engineering Structures 30(3): 804-820. http://dx.doi.org/10.1016/j.engstruct.2007.05.021

British Standards Institution. 1996. BS 6399-1:1996 Code of practice for dead and imposed loads. London: BSI.

British Standards Institution. 1997. BS 6399-2:1997 Code of practice for wind loads. London: BSI.

Computers and Structures Inc. 1995. CSI analysis reference manual. Berkeley, CA: Computers and Structures Inc.

Dolšek, M.; Fajfar, P. 2008a. The effect of masonry infills on the seismic response of a four-storey reinforced concrete 
frame - a deterministic assessment, Engineering Structures 30(7): 1991-2001.

http://dx.doi.org/10.1016/j.engstruct.2008.01.001

Dolšek, M.; Fajfar, P. 2008b. The effect of masonry infills on the seismic response of a four-storey reinforced concrete frame - a probabilistic assessment, Engineering Structures 30(11): 3186-3192.

http://dx.doi.org/10.1016/j.engstruct.2008.04.031

Fraser, C. 1985. D'Alembert's principle: the original formulation and application in Jean d'Alembert's Traeatise on dynamics (1743), Centaurus 28(2): 145-159. http://dx.doi.org/10.1111/j.1600-0498.1985.tb00834.x

Guan, H.; Cooper, C.; Lee, D. J. 2010. Ultimate strength analysis of normal and high strength concrete shear wall panels with varying opening configurations, Engineering Structures 32(5): 1341-1355.

http://dx.doi.org/10.1016/j.engstruct.2010.01.012

Islam, A. B. M. S.; Hussain, R. R.; Jameel, M.; Jumaat, M. Z. 2012a. Non-linear time domain analysis of base isolated multi-storey building under site specific bi-directional seismic loading, Automation in Construction 22: 554-566. http://dx.doi.org/10.1016/j.autcon.2011.11.017

Islam, A. B. M. S.; Jameel, M.; Uddin, M. A.; Jumaat, M. Z. 2012b. Competent building elevation for incorporating base isolation in aseismic structure, Procedia Engineering 50: 882-892. http://dx.doi.org/10.1016/j.proeng.2012.10.096

Islam, A. B. M. S.; Hussain, R. R.; Jumaat, M. Z.; Rahman, M. A. 2013a. Nonlinear dynamically automated excursions for rubber-steel bearing isolation in multi-storey construction, Automation in Construction 30: 265-275.

http://dx.doi.org/10.1016/j.autcon.2012.11.010

Islam, A. B. M. S.; Jameel, M.; Jumaat, M. Z.; Rahman, M. M. 2013b. Optimization in structural altitude for seismic base isolation at medium risk earthquake disaster region, Disaster Advances 6(1): 23-34.

Jameel, M.; Islam, A. B. M. S.; Hussain, R. R.; Khaleel, M. 2011. Optimum structural modelling for tall buildings, The Structural Design of Tall and Special Buildings 22(15): 1173-1185.

Kim, T.; Foutch, D. A. 2007. Application of FEMA methodology to RC shear wall buildings governed by flexure,
Engineering Structures 29(10): 2514-2522.

http://dx.doi.org/10.1016/j.engstruct.2006.12.011

Kim, H.-S.; Lee, D.-G. 2003. Analysis of shear wall with openings using super elements, Engineering Structures 25(8): 981-991. http://dx.doi.org/10.1016/S0141-0296(03)00041-5

Kim, H.-S.; Lee, D.-G. 2005. Efficient analysis of flat slab structures subjected to lateral loads, Engineering Structures 27(2): 251-263. http://dx.doi.org/10.1016/j.engstruct.2004.10.005

Kim, H.-S.; Lee, D.-G.; Kim, C.-K. 2005. Efficient threedimensional seismic analysis of a high-rise building structure with shear walls, Engineering Structures 27(6): 963-976. http://dx.doi.org/10.1016/j.engstruct.2005.02.006

Kim, S. B.; Lee, Y. H.; Scanlonc, A.; Kim, H.; Hong, K. 2008. Experimental assessment of vibration serviceability of stair systems, Journal of Constructional Steel Research 64(2): 253-259. http://dx.doi.org/10.1016/j.jcsr.2007.07.003

Kose, M. M. 2009. Parameters affecting the fundamental period of RC buildings with infill shear walls, Engineering Structures 31(1): 93-102. http://dx.doi.org/10.1016/j.engstruct.2008.07.017

Lin, L.-L.; Chang, C.-C.; Lin, Y.-C. 2011. Structure development and performance evaluation of construction knowledge management system, Journal of Civil Engineering and Management 17(2): 184-196. http://dx.doi.org/10.3846/13923730.2011.576833

Madsen, L. P. B.; Thambiratnam, D. P.; Perera, N. J. 2003. Seismic response of building structures with dampers in shear walls, Computers \& Structures 81(4): 239-253. http://dx.doi.org/10.1016/S0045-7949(02)00441-8

Shariq, M.; Abbas, H.; Irtaza, H.; Qamaruddin, M. 2008. Influence of openings on seismic performance of masonry building shear walls, Building and Environment 43(7): 1232-1240. http://dx.doi.org/10.1016/j.buildenv.2007.03.005

Wang, Q.; Wang, L.; Liu, Q. 2001. Effect of shear wall height on earthquake response, Engineering Structures 23(4): 376-384. http://dx.doi.org/10.1016/S0141-0296(00)00044-4

Mohammed JAMEEL did his PhD from Indian Institute of Technology Delhi (IIT Delhi), India. He has successfully completed various sponsored projects involving non-linear analysis of TLPs, Spar, FPSO platforms, deep and shallow water mooring lines and risers. The projects were supported by several government and private funding agencies. His research area includes non-linear dynamics, earthquake engineering, reliability engineering, offshore structures, artificial neural network and non-linear finite element analysis. Presently, he is associated with Department of Civil Engineering, University of Malaya, Malaysia.

Dr. A. B. M. Saiful ISLAM He is a PhD and is working as a Research Fellow at the Department of Civil Engineering, University of Malaya, Malaysia. He completed his BSc in Civil Engineering and MSc in Structural Engineering from Bangladesh University of Engineering and Technology (BUET), Bangladesh. He is a member of Institution of Engineers, Bangladesh and American Society of Civil Engineers (ASCE). His research interests include offshore structures, non-linear dynamics, finite element modelling, seismic protection, base isolation and pounding and special tall buildings.

Mohammed KHALEEL He did his Masters in Structural Engineering from Jawaharlal Nehru Technological University, India. He is currently pursuing doctorate from the University of Malaya, Malaysia. His research interests include non-linear finite element analysis, reliability analysis, tall structures, offshore structures and pre-cast concrete structures.

Dr. Aslam AMIRAHMAD is an accomplished academician who had joined the Civil Engineering Department of Salman Bin Abdulaziz University, Al-Kharj, as a Professor. Assuming charge on 1 December 2008, Dr. Aslam had set his goals to develop the Department of Civil Engineering as a team of talented and dedicated Faculty members and to take the Civil Engineering Department to new heights, among the top Departments of Salman Bin Abdulaziz University. He has done his U.G. and P.G. Degrees in Civil Engineering from Aligarh Muslim University Aligarh and PhD from Indian Institute of Technology Delhi. 